\title{
CANCER RISK ASSOCIATED WITH LIVING AT HIGH ALTITUDE IN ECUADORIAN POPULATION FROM 2005 TO 2014
}

\author{
DAVID ISRAEL GARRIDO, SANTIAGO MOISES GARRIDO
}

\author{
Rural Medicine Service, Ministry of Public Health, Ecuador
}

\begin{abstract}
Background and aims. Cancer is a leading cause of death in Ecuador with high social and economic impact. This study aims to determinate the influence of living at a high altitude on the risk of developing or dying from cancer among the Ecuadorian population.

Methods. This is an ecological and epidemiological analysis of cancer mortality and prevalence rates, based on national data from the Ecuadorian National Statistics and Census Institute, corresponding to the period between 2005 and 2014. This study includes the analysis of various types of cancer: gastric, colorectal, hepatic/ bile duct, breast, uterine/cervix, and lymphatic/hematopoietic, using rates of mortality and prevalence. Additionally, the association between the risk of getting or dying from cancer and living at high altitude was investigated. This comparison was made between the population living in Highlands, over 2000 meters above sea level, and low-lying regions.

Results. Living at high altitude was associated with a higher prevalence of cancer and also with a high mortality rate due to cancer. Risk of getting cancer was related to living at a higher altitude, as well as an increased risk of death by cancer: gastric (OR:1.204; $p<0.001)$, colorectal (OR:1.421; $p<0.001)$, hepatic/bile duct (OR:1.184; $p<0.001)$, breast (OR:1.067; $p=0.030)$, or lymphatic/hematopoietic neoplasms (OR:1.135; $p<0.001)$.

Conclusions. Through an epidemiologic analysis, the association between developing or dying from cancer and living at high altitude was obtained. However, further researche is needed to clarify these findings, something that could have a substantial impact on cancer prevention.
\end{abstract}

Keywords: cancer, altitude, mortality, prevalence, Ecuador

\section{Background and aims}

Cancer is one of the leading causes of death worldwide, with an increasing prevalence as a result of the greater life expectancy, genetic and environmental risk factors, along with pro-carcinogenic habits adoption in the population [1]. As $69 \%$ of deaths in Latin America and the Caribbean result from chronic non-communicable diseases, such as hypertension, diabetes, and cancer, it is important to understand the different risk factors associated with each population group and how environmental conditions affect the prevalence and mortality of these diseases [2]. In the past ten years, some studies have investigated the possible

Manuscript received: 18.11.2017

Accepted: 18.12.2017

Address for correspondence: david_labinmuno@hotmail.com risk association between geographic altitude and cancer. However, contradicting results have been reported in which the expression of hypoxia-inducible factors (HIFs), Vitamin D activity, ultraviolet (UV) radiation effect, or even oxygen toxicity and physiological changes in $\mathrm{pH}$, were considered as a possible explanation [3]. Nevertheless, these studies do not demonstrate a risk association between getting or dying from cancer in the Ecuadorian Andean population. Studies directed to clarify the effect of living at high altitude in different populations would be necessary for the enrichment of cancer therapeutics and prevention, something that might be valuable as cancer occupies several positions among the leading causes of mortality.

The objective of this study is to determine the influence of living at a higher geographical altitude on 
the risk of developing and dying from cancer among the Ecuadorian population as the result of breast, cervix, stomach, colorectal, liver and bile duct, and hematopoietic cancer.

\section{Methods}

We performed an ecological study conducted between October 2016 and May 2017, at Quito, Ecuador, using an epidemiological, descriptive and retrospective design, based on the association of prevalence and mortality rates in high altitude provinces compared to low altitude provinces from Ecuador.

Living at high altitude was considered the exposure factor. Therefore, we classified all the data according to the region in highland regions (HR) and low-lying regions (LR); these two groups were used during all the comparisons and risk associations made in this study.

\section{Study Location}

Ecuador is a country crossed by the Andes mountains, a feature that places the regions at different altitudes above sea-level (Figure 1); HR and LR. The HR, also known as Sierra, comprising 10 provinces, is located in the foothills and valleys of the Andes Mountains, with its population situated at an altitude ranging from 600 to 5000 masl (meters above sea-level) and the highest population density over 2000 masl. Additionally, the LR that include: Coastal, Amazon and insular areas (Galapagos), constitute
14 provinces located at an altitude ranging from 0 to 1000 masl, with the highest population density concentrated in cities below 600 masl [4].

\section{Data extraction}

The data were extracted from the database created by the Instituto Nacional de Estadísticas y Censos del Ecuador (Ecuadorian National Statistics and Census Institute) (INEC) employing the REtrieval of DATa for Small Areas by Microcomputer (REDATAM) system, published and available at the web portal of the institution. Data corresponding to the period between 2005 and 2014 were selected $[5,6,7]$. Such data, according to INEC, were provided by 780 public and private institutions nationally.

From the total number of published variables, the following annual data were selected: (a) Total population by province; (b) total number of hospital discharges by province; (c) number of hospital discharges by province, specifically for the following types of cancer: Stomach, colorectal, breast, cervix, liver and intrahepatic biliary tract, and lymphatic and hematopoietic tissues; (d) number of deaths registered by province; (e) number of deaths by province due to the following types of cancer: Stomach, colorectal, breast, cervix, liver and intrahepatic biliary tract, and lymphatic and hematopoietic tissues. We excluded the data obtained from Ecuadorians residing abroad (1.94\% of the population) and inhabitants of un-demarcated zones $(0.22 \%$ of the population).

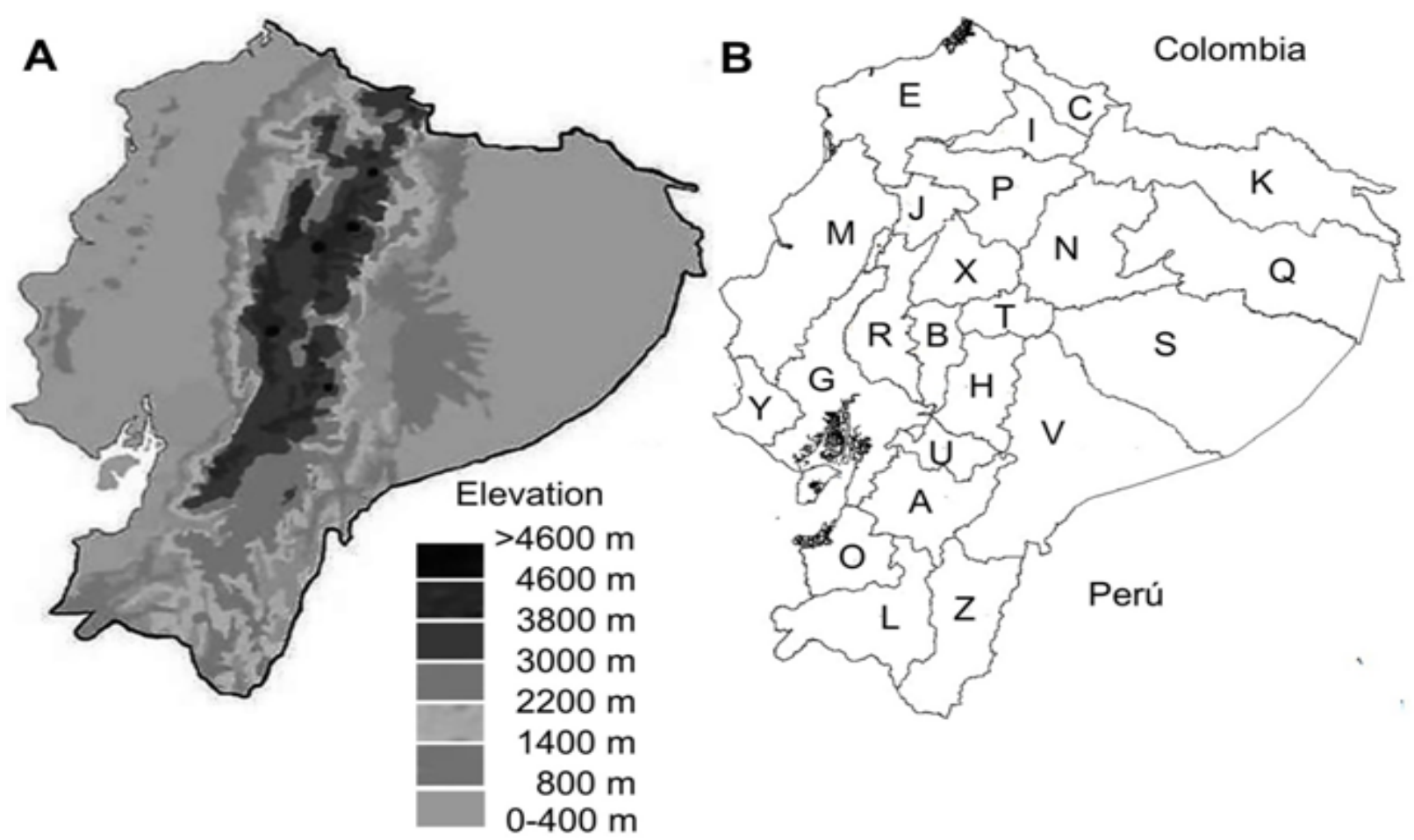

Figure 1. Geographic differences and provincial division of Ecuador. A. Hypsometric map of Ecuador, geographic altitudes are shown in different tonalities. B. Provincial division of Ecuador. Low-lying regions; E: Esmeraldas; M: Manabí; Y: Santa Elena; G: Guayas; R: Los Ríos; O: El Oro; K: Sucumbíos; Q: Francisco de Orellana; S; Pastaza; V: Morona Santiago; Z: Zamora Chinchipe; J: Santo Domingo de los Tsáchilas. Highlands región; C, Carchi; I, Imbabura; P, Pichincha; X, Cotopaxi; T, Tungurahua; B, Bolívar; H, Chimborazo; U, Cañar; A, Azuay; L, Loja. Galapagos is not presented in the map. 


\section{Prevalence and mortality rates}

On account of the different population density among both established groups, data were standardized and presented as epidemiological rates, calculating the overall prevalence of all cancer types included in this study, and those specific epidemiological rates in each kind of cancer investigated per province, according to the following formula [8]:

Prevalence:(All cases of the disease in the established period $) /($ Total population at the midpoint of the time period)

Similarly, the overall mortality for all types of cancer and specifically to each type of cancer was investigated per province, calculated through the formula [8]:

Mortality:(Total deaths due to the disease in the established period)/(Total population at the midpoint of the time period)

The rates calculated were expressed in the number of cases and deaths for every 100000 inhabitants. The results of prevalence and mortality were averaged by province, group, and total years.

\section{Data analysis and statistics}

The statistical significance was determined using the SPSS v.20 software package, using the mean differences (MD) among the rates calculated in the groups, and t test. Furthermore, with the values of the population diagnosed and deceased, according to each type of cancer investigated, as well as the population not affected by the types of cancer analyzed, the risk association was calculated using the Odds
Ratio (OR).

\section{Results}

Between the years 2005 and 2014, in Ecuador, an annual average of 2498 cases of colorectal cancer, 3324 cases of stomach cancer, 4968 cases of breast cancer, 724 cases of lymphatic and hematopoietic cancer, 2082 cases of cervix cancer, and 732 cases of liver/biliary tract cancer were recorded for an average population of 14584069 inhabitants, and 997666 hospital discharges reported nationally during the ten year period. Breast cancer presented the highest rate of prevalence among the types of cancer investigated nationally, appearing on an average of 430/100 000 (95\% CI: 429.30430.69) followed by stomach cancer with a prevalence about 369/100 000 (95\% CI: 368.01-369.59). Moreover, an annual average of 14217 deaths was reported throughout the country. Besides, stomach cancer mortality was the highest among the studied group, with a rate of 11/100 000 (95\% CI: 10.94-11.01), followed by liver and biliary tract cancer, with a mortality rate of 4/100 000 (95\% CI: 3.99-4.01).

Cancer prevalence and mortality rates in Ecuador

According to the prevalence and mortality rates for each cancer type and province, the province of Loja presented the highest prevalence of all kinds of cancer included followed by Azuay (Figure 2). These rates differ significantly from the national average. As regards mortality, the province of Carchi presented the highest rate of mortality for all types of cancer studied followed by the province of Imbabura (Figure 3).



Figure 2. Cancer prevalence rates in Ecuador classified by provinces. This figure only includes the prevalence rates for the average of all the cancer types included in this study (stomach, colorectal, breast, cervix, liver and intrahepatic biliary tract, and lymphatic and hematopoietic tissues). Prevalence rates expressed using number of cases over 100000 habitants. HABS: habitants; FCO: Francisco. 


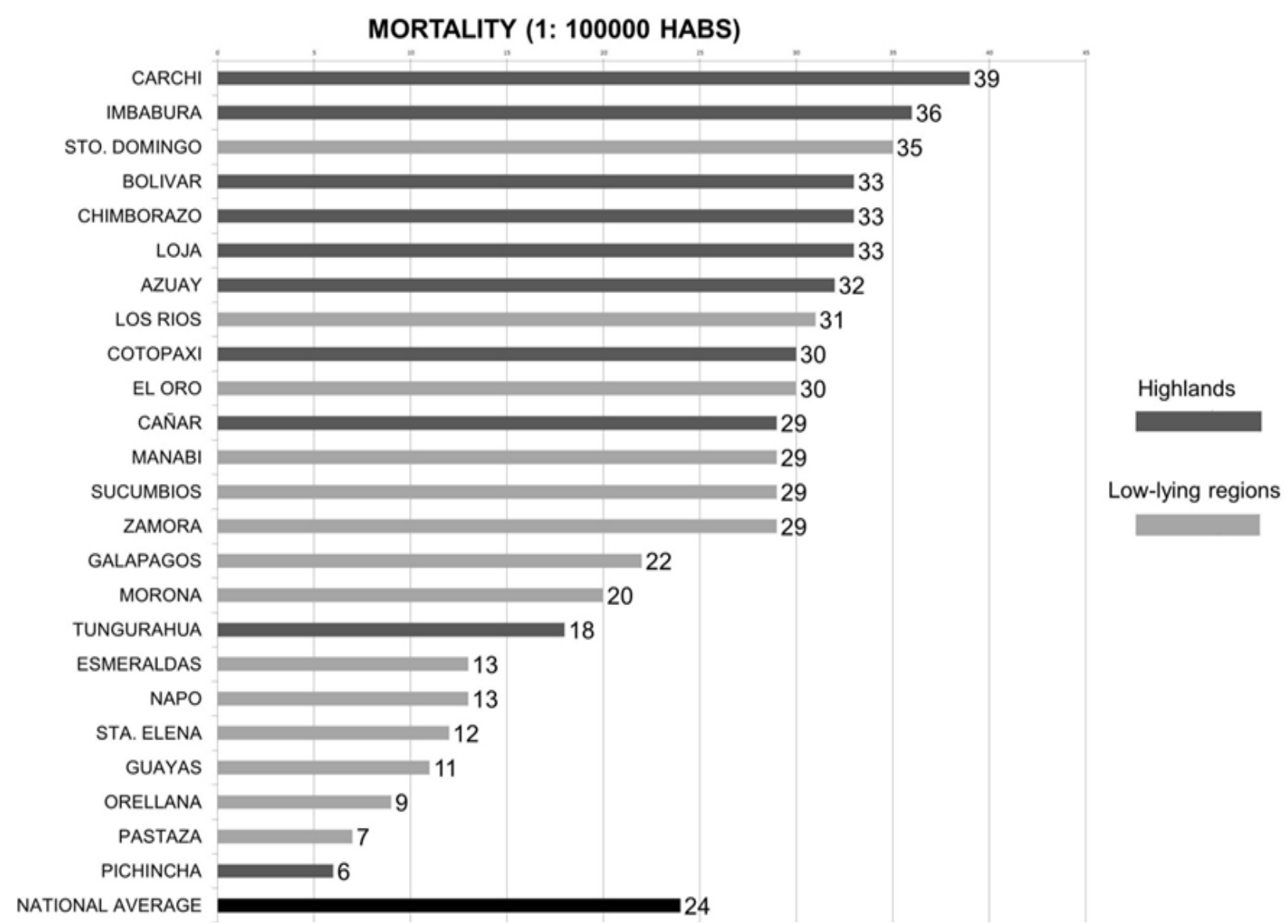

Figure 3. Cancer mortality rates in Ecuador classified by provinces. This figure only includes the mortality rates for the average of all the cancer types included in this study (stomach, colorectal, breast, cervix, liver and intrahepatic biliary tract, and lymphatic and hematopoietic tissues). Mortality rates expressed using number of cases over 100000 habitants. HABS: habitants; FCO: Francisco.

\section{highlands}

High prevalence of cancer in Ecuadorian south

The prevalence values obtained for all the types of cancer included were very high in the southern area of the HR. Thus, we divide this area into two subgroups; Northern Highlands (includes the five provinces of the Ecuadorian highlands: Carchi, Imbabura, Pichincha, Cotopaxi, and Tungurahua) and the southern highlands (includes five southern provinces of the Ecuadorian highlands: Chimborazo, Bolívar, Cañar, Azuay, and Loja). The statistical analysis was performed according to the detailed methodology.

Mean difference between prevalence and mortality rates of cancer obtained for groups according to geographic altitude.

The prevalence of all types of cancer studied was higher in the HR compared to the population of the LR; significantly for breast cancer and stomach cancer. Similarly to the prevalence comparison between the southern highland group and those from the low-lying regions (Table I).

On comparing the mortality rates, the overall mortality rate for all types of cancer was significantly higher in the highland group as compared to the group in the lowlying regions. As for the southern highland subgroup, it was demonstrated a higher mortality rate on an average for all types of cancer compared to the group from the low-lying region; with no statistical difference for colorectal cancer, cervical cancer, myeloma or plasma cell cancer (Table I).

Odds Ratio of living at high altitude associated as risk factor for getting cancer or dying by cancer.

It was established a higher risk of contracting cancer for inhabitants from the group of provinces in the highlands as compared to those in the low-lying regions; being greater for liver and biliary tract cancer. Additionally, there was higher risk of contracting cancer for the southern highland subgroup, especially for stomach cancer. Comparatively, it was demonstrated that there was no risk for any type of cancer in the northern highlands subgroup as compared to the groups from the low-lying regions. However, analyzing each type of cancer, it was determined more risk of contracting stomach cancer and liver/biliary tract cancer in the northern highlands subgroup compared to low-lying regions population (Table II). 


\section{Public Health}

Table I. Mean difference between prevalence and mortality rates due to cancer obtained for groups according to geographic altitude ( $95 \% \mathrm{CI})$.

\begin{tabular}{|c|c|c|c|c|c|c|}
\hline $\mathbf{A}$ & \multicolumn{3}{|c|}{ Prevalence Comparison } & \multicolumn{3}{|c|}{ Mortality comparison } \\
\hline Cancer type & $\mathrm{MD} /(\mathrm{L}-\mathrm{H})$ & $95 \% \mathrm{CI}$ & $P$ & $\mathrm{MD} /(\mathrm{L}-\mathrm{H})$ & $95 \% C I$ & $P$ \\
\hline Gastric & 7.0 & $4.09 ; 9.87$ & $<0.01 *$ & 7.8 & $6.62 ; 8.94$ & $<0.01 *$ \\
\hline Colorectal & 3.0 & $0.36 ; 5.68$ & $<0.01 *$ & 0.8 & $0.17 ; 1.47$ & $<0.01 *$ \\
\hline Hepatic/bile duct & 1.9 & $1.37 ; 2.36$ & $<0.01 *$ & 2.5 & $1.91 ; 3.02$ & $<0.01 *$ \\
\hline Breast cancer & 9.8 & $5.12 ; 14.53$ & $<0.01 *$ & 1.0 & $0.62 ; 1.35$ & $<0.01^{*}$ \\
\hline Uterine cervix & 3.4 & $1.34 ; 5.53$ & $<0.01 *$ & 1.3 & $0.78 ; 1.90$ & $<0.01 *$ \\
\hline Lymphatic/hematopoietic & 1.6 & $0.83 ; 2.35$ & $<0.01 *$ & 0.8 & $0.09 ; 1.44$ & $0.02 *$ \\
\hline Average & 4.5 & $2.19 ; 6.72$ & $<0.01^{*}$ & 2.4 & $1.69 ; 3.02$ & $<0.01^{*}$ \\
\hline $\mathbf{B}$ & \multicolumn{3}{|c|}{ Prevalence Comparison } & \multicolumn{3}{|c|}{ Mortality comparison } \\
\hline Gastric & 0.6 & $-2.43 ; 3.69$ & 0.7 & 7.5 & $5.93 ; 9.11$ & $<0.01 *$ \\
\hline Colorectal & -1.4 & $-3.62 ; 0.77$ & 0.4 & 2.8 & $0.26 ; 1.51$ & $<0.01^{*}$ \\
\hline Hepatic/bile duct & 1.3 & $0.78 ; 1.93$ & $<0.01 *$ & 2.9 & $2.28 ; 3.58$ & $<0.01 *$ \\
\hline Breast cancer & -2.1 & $-6.06 ; 1.93$ & 0.3 & 1.3 & $1.31 ; 1.78$ & $<0.01^{*}$ \\
\hline Uterine cervix & -2.4 & $-4.39 ;-0.38$ & $0.02 *$ & 2.0 & $1.31 ; 2.79$ & $<0.01 *$ \\
\hline Lymphatic/hematopoietic & 0.1 & $-0.56 ; 0.84$ & 0.7 & 0.9 & $0.43 ; 1.79$ & $0.04 *$ \\
\hline Average & -0.6 & $-2.71 ; 1.45$ & 0.3 & 2.9 & $7.57 ; 15.96$ & $<0.01 *$ \\
\hline $\mathbf{C}$ & \multicolumn{3}{|c|}{ Prevalence Comparison } & \multicolumn{3}{|c|}{ Mortality comparison } \\
\hline Gastric & 13.3 & $9.64 ; 17.02$ & $<0.01 *$ & 8.0 & $6.57 ; 9.53$ & $<0.01 *$ \\
\hline Colorectal & 7.5 & $3.95 ; 10.99$ & $<0.01 *$ & 0.8 & $-0.13 ; 1.67$ & $<0.01 *$ \\
\hline Hepatic/bile duct & 2.4 & $1.77 ; 3,06$ & $<0.01 *$ & 2.0 & $1.26 ; 2.75$ & $<0.01 *$ \\
\hline Breast cancer & 21.7 & $13.85 ; 29.58$ & $<0.01 *$ & 0.7 & $0.29 ; 1.13$ & $<0.01 *$ \\
\hline Uterine cervix & 9.3 & $6.20 ; 12.30$ & $<0.01 *$ & 0.7 & $-0.01 ; 1.34$ & 0.05 \\
\hline Lymphatic/hematopoietic & 3.0 & $1.74 ; 4.34$ & $<0.01 *$ & 0.6 & $-0.21 ; 1.44$ & 0.14 \\
\hline Average & 9.5 & $6.19 ; 12,88$ & $<0.01 *$ & 2.1 & $1.29 ; 2.97$ & 0.05 \\
\hline
\end{tabular}

Note. This table presents the mean difference value obtained through the comparison of prevalence and mortality rates due to cancer obtained for groups according to geographic altitude; L-H: Highland Region tendency is located to the right side of 0; P: p-value; A: Highlands vs Lowlying Regions; B: Northern Highlands vs Low-lying Regions; C: Southern Highlands vs Low-lying Regions ; CI: Confidence interval; MD: Mean difference; *Significant value

Table II. Odds Ratio of living at high altitude associated as risk factor for getting cancer $(95 \% \mathrm{CI})$. High altitude as exposure factor.

\begin{tabular}{|c|c|c|c|c|c|c|}
\hline $\mathbf{A}$ & \multicolumn{3}{|c|}{ Prevalence Comparison } & \multicolumn{3}{|c|}{ Mortality comparison } \\
\hline Cancer type & OR/(L-H) & $95 \% C I$ & $P$ & $\mathrm{OR} /(\mathrm{L}-\mathrm{H})$ & $95 \% C I$ & $P$ \\
\hline Gastric & 1.1 & $1.08 ; 1.15$ & $<0.01^{*}$ & 1.2 & $1.19 ; 1.27$ & $<0.01^{*}$ \\
\hline Colorectal & 1.6 & $1.52 ; 1.68$ & $<0.01^{*}$ & 1.4 & $1.35 ; 1.49$ & $<0.01^{*}$ \\
\hline Hepatic/bile duct & 1.2 & $1.13 ; 1.28$ & $<0.01^{*}$ & 1.2 & $1.13 ; 1.24$ & $<0.01^{*}$ \\
\hline Breast cancer & 1.1 & $1.03 ; 1.18$ & $<0.01^{*}$ & 1.1 & $1.01 ; 1.13$ & $0.03 *$ \\
\hline Uterine cervix & 1.1 & $1.06 ; 1.13$ & $<0.01^{*}$ & 1.0 & $0.94 ; 1.06$ & $0.04 *$ \\
\hline Lymphatic/hematopoietic & 1.7 & $1.57 ; 1.75$ & $<0.01^{*}$ & 1.1 & $1.06 ; 1.22$ & $<0.01 *$ \\
\hline Average & 1.3 & $1.23 ; 1.34$ & $<0.01^{*}$ & 1.2 & $1.11 ; 1.24$ & $<0.01^{*}$ \\
\hline $\mathbf{B}$ & \multicolumn{3}{|c|}{ Prevalence Comparison } & \multicolumn{3}{|c|}{ Mortality comparison } \\
\hline Gastric & 0.9 & $0.83 ; 0.93$ & $<0.01^{*}$ & 1.2 & $1.16 ; 1.23$ & $<0.01^{*}$ \\
\hline Colorectal & 1.2 & $1.18 ; 1.26$ & $<0.01^{*}$ & 1.6 & $1.49 ; 1.66$ & $<0.01^{*}$ \\
\hline Hepatic/bile duct & 1.0 & $0.89 ; 1.02$ & 0.1 & 1.2 & $1.12 ; 1.24$ & $<0.01 *$ \\
\hline Breast cancer & 0.6 & $0.52 ; 0.67$ & $<0.01^{*}$ & 1.1 & $1.03 ; 1.16$ & $<0.01 *$ \\
\hline Uterine cervix & 0.6 & $0.58 ; 0.65$ & $<0.01^{*}$ & 1.1 & $0.99 ; 1.12$ & 0.09 \\
\hline Lymphatic/hematopoietic & 1.5 & $1.43 ; 1.63$ & $<0.01^{*}$ & 1.2 & $1.08 ; 1.26$ & $<0.01 *$ \\
\hline Average & 1.0 & $0.93 ; 1.02$ & 0.2 & 1.1 & $1.10 ; 1.26$ & $<0.01 *$ \\
\hline $\mathbf{C}$ & \multicolumn{3}{|c|}{ Prevalence Comparison } & \multicolumn{3}{|c|}{ Mortality comparison } \\
\hline Gastric & 1.6 & $1.58 ; 1.71$ & $<0.01^{*}$ & 1.5 & $1.43 ; 1.53$ & $<0.01^{*}$ \\
\hline Colorectal & 2.3 & $2.19 ; 2.33$ & $<0.01^{*}$ & 0.8 & $0.77: 0.89$ & $<0.01^{*}$ \\
\hline Hepatic/bile duct & 1.7 & $1.59 ; 1.83$ & $<0.01^{*}$ & 1.2 & 1.53: 1.29 & $<0.01 *$ \\
\hline Breast cancer & 1.9 & $1.84 ; 1.93$ & $<0.01^{*}$ & 0.9 & $0.79 ; 0.93$ & $<0.01 *$ \\
\hline Uterine cervix & 2.1 & $1.98 ; 2.14$ & $<0.01^{*}$ & 1.0 & $0.89 ; 1.04$ & 0.36 \\
\hline Lymphatic/hematopoietic & 1.9 & $1.78 ; 2.06$ & $<0.01^{*}$ & 1.2 & $1.08 ; 1.26$ & $<0.01^{*}$ \\
\hline Average & 1.9 & $1.83 ; 2.01$ & $<0.01^{*}$ & 1.2 & $1.07 ; 1.24$ & $<0.01 *$ \\
\hline
\end{tabular}

Note. This table presents the Odds Ratio of living at high altitude associated as risk factor for getting cancer through the comparison of prevalence and mortality rates due to cancer obtained for groups according to geographic altitude; L-H: Highland Region tendency is located to the right side of 1; P: p-value; A: Highlands vs Low-lying Regions; B: Northern Highlands vs Low-lying Regions; C: Southern Highlands vs Low-lying Regions; CI: Confidence interval; MD: Mean difference; *Significant value. Living at high altitude is considered the exposure factor. 
As regards the risk of death due to cancer, the inhabitants of the highland regions presented higher risk of dying from all types of investigated cancer compared to inhabitants of low-lying regions. The inhabitants of the northern highland group presented, on an average, 1.13 times more risk of death from all types of cancer included, except cervical cancer. Additionally, for inhabitants of the southern highland region, there was more risk of dying from cancer, which was very significant for stomach cancer, liver and biliary tract cancer, as well as myeloma and plasma cell cancer, as compared to low-lying regions population (Table II).

\section{Discussion}

In an effort to understand how geographical altitude influences the development of cancer, we performed an epidemiological and ecological analysis, made on the basis of Ecuadorian registers of patients hospitalized for this condition. Our data reported an increased incidence of colon, gastric, lymphatic, hematopoietic, liver, biliary system, uterine, and breast cancer among the population living in the highlands, and also, a significant increase in mortality rates and risk of death from cancer associated with living at a geographic altitude greater than 2000 masl, which was demonstrated in a majority of the types of cancer included in this study.

Hypoxic conditions in high altitude, and Hypoxia

\section{Inducible Factors (HIFs) activity in cancer}

One of the reasons we considered for the explanation of this phenomenon was the effect of the hypobaric and hypoxic conditions in which the inhabitants of higher geographic altitudes lived [9]. Cellular hypoxia could alter the genetic transcription or produce post-translational protein changes. Moreover, HIFs are the most important regulators of cellular response to oxygen $(\mathrm{O} 2)$. Among the consequences of HIF stabilization, the cells subject to hypoxia could express genes responsible for cellular proliferation, angiogenesis, metastasis, and metabolism [10].

The increase in HIF availability is a constant that remains conserved in populations living at higher geographic altitudes [11]. In addition, there is a decrease in the $\mathrm{O} 2$ supply in neoplasms that show rapid growth. In this case HIF- $1 \alpha$ assists those tumor cells by changing the metabolism of glucose, increasing the angiogenesis and also improving the conditions to metastasis [12]. Angiogeny mediated by HIF- $1 \alpha$ is the result of the transcriptional induction of pro-angiogenic genes, among which the Vascular Endothelia Growth Factor (VEGF) is highlighted. Additionally, HIF-1 $\alpha$ favors metastasis through the expression of oncogenic growth factors [13]. All these characteristics attributed to HIFs can increase tumor aggressiveness, tissue expansion, metastasis, and also increase resistance to radio- and chemotherapy, which may explain the higher mortality as well as the increased risk of dying from cancer, which we have identified in the
Ecuadorian population that lives over 2000 masl, [14].

The types of cancer that have remained equally significance in the comparisons made in our study are stomach, liver and biliary tract, and breast. A study (Nakamura, 2010) that analyzed 91 samples from a stomach cancer resection demonstrated a greater expression of HIF-1 $\alpha$ in patients with poor improvement and survival $(\mathrm{p}=0.026$ and $\mathrm{p}=0.014$, respectively) [15]. This result is consistent with our outcome and with the evidence in those countries which are part of the mountainous regions of Pacific Latin America, where the areas at a higher geographic altitude have elevated rates of this type of cancer, except in Mexico and Chile [16]. With respect to the hepatic neoplasms (Ryu, 2008), the expression of metastatic tumor antigen-1 (MTA1), a stabilizer of HIF-1 $\alpha$ activity in Hepatocellular carcinoma (HCC), was associated with larger tumors $(\mathrm{p}=0.04)$, microvascular invasion $(\mathrm{p}=$ $0.008)$, greater recurrence $(\mathrm{p}<0.0001)$, and less survival $(\mathrm{p}<0.0001)$, even with Hepatitis B Virus (HBV) infection $(p=0.017)[17]$. As regards the biliary tract (Thongchot, 2014), the expression of HIF-1 $\alpha$ is associated with greater metastasis and poor prognosis in cholangiocarcinoma $(\mathrm{p}<$ 0.05 ) [18], data that is concordant with the results found in our study. Aditionally, a study (Dales, 2005) that included 745 patients demonstrated that the expression of HIF-1 $\alpha$ is a predictor of metastasis risk $(\mathrm{p}=0.03)$ and relapse $(\mathrm{p}$ $=0.035$ ) in breast cancer [19]. New studies are required to determinate the use of cancer therapy based on the direct or indirect inhibition of HIF pathways, or the use of oxygen as adjuvant in neoplastic control.

\section{Cancer prevalence and mortality in South HR; a problem to investigate}

Upon subdividing the HR into Northern and Southern sub-regions, we observed the difference in the mortality and prevalence of various types of cancers. Particularly in Azuay and Loja. The cause for this difference is inexplicable through the methodology used in this work. However, some reason could be; illegal mining and subsequent contamination of water sources in several populations at the southern highlands, ethnic population of each region and their sociocultural characteristics, and the frequency of risk factors for each type of cancer established in particular communities. However, there is a lack of publications on the Ecuadorian population to explain this effect.

\section{Radiation in Ecuadorian high altitude}

Other factors that should be considered in the Ecuadorian Andean population are exposure to intense solar radiation $[20,21]$. Unlike in our findings, some studies demonstrate that solar radiation reduces the risk of cancers of the digestive tract organs, breast, and leukemia, but an increased risk of cervical, uterine, and liver cancer was suggested [22]. However, the amount of solar radiation in the Ecuadorian highlands tends to be different in comparison to where these studies were conducted [23]. 
There are no available investigations on the effect of solar radiation and the risk of cancer in our population.

In contrast to our results, studies in the United States of America have suggested greater protection against cancer in populations living at a higher geographical altitude [24]. This could be explained by vitamin D activity, which has an anti-neoplastic effect through decreasing cancer progression, angiogenesis, and tumor migration, however, inconsistent results exist in the epidemiological studies and clinical trials that demonstrate its benefit [25].

Influence of diet and infectious diseases in Ecuadorian population

The quality of diet has been associated with the improvement of health in cancer patients. An inflammatory diet, characterized by sugar, refined starches, saturated, and trans-fatty acids, low antioxidants, poor fiber, and lack of omega-3 fatty acids, causes an increased production of pro-inflammatory and inflammatory biomarkers [26]. This is associated with an increased risk of colorectal cancer [27], while the intake of foods containing dietary fiber decreases the risk of this condition [28]. The higher fiber and polyphenol intake is also associated with a decreased risk of breast cancer [29]. The fruit- and vegetable-based diets have a protective effect in gastric cancer, but $\mathrm{H}$. pylori is a significant risk factor [30]. In addition, the presence of $\mathrm{H}$. Pylori is remarkable in the Ecuadorian population [31]. It is important to consider that in Latin America, hepatitis $\mathrm{B}$ and $\mathrm{C}$ virus infection is a growing health problem and remains unknown its impact on the prevalence and mortality of liver cancer in our population [32]. Another important pathogen is the Human Papilloma Virus (HPV), which in Latin America is strongly associated with cervical cancer $[33,34,35]$.

According to the ENSANUT-ECU 2012 (Encuesta Nacional de Salud y Nutrición-Ecuador 2012, National Health and Nutrition Survey-Ecuador 2012) report, a diet based on carbohydrates and refined starches and insufficient consumption of fiber is a constant in all the Ecuadorian regions. Nevertheless, there are undeniable regional differences according to dietary habits and consumption of different nutritional products. Another report of ENSANUT-ECU 2012 shows the consumption of alcohol in Ecuador varies from $45.1 \%$ to $72.7 \%$, being very uniform among all the provinces [36]. However, further studies are needed in which these two variables, diet, and infectious diseases show influence on people suffering or dying from cancer. It is important also to consider that the Amazon region has the largest oil industry in the country. So, we believe necessary that future studies assess the condition of the Amazonian population.

\section{Lack of access to health services}

A problem that should be considered analyzing our results is the possible lack of access to specialized services in some populations of the LR, which obligates oncologic patient to migrate to HR searching for an integral and more specialized treatment in cities such as Quito and Cuenca. However, we don't have enough information to affirm this idea.

The lack of access to health services in cancer control certainly is also a public health problem with high economic and social impact. Therefore, is necessary the identification of the limiting factors in health access, mainly in rural communities.

\section{Limitations}

This study has important limitations that must be considered, as they are: The absence of tumor markers, diagnostic criteria, and clinical manifestations in the data we used, which exclude dietary, socioeconomic, ethnics, and infection by pro-carcinogenic viruses or bacteria, in the patients included in this study. It is important for subsequent research to use the data that each medical record can provide. Among the questions that have been generated by this study are the need to study the variation of HIF expression at different heights in the Ecuadorian population, as well as to determine how the levels of vitamin $\mathrm{D}$ vary, and the effect that it has, along with radiation, on neoplastic genesis. To this we should add the absence of available data regarding genetic, epigenetic, and infectious mechanisms and their impact on the studied population. We consider it necessary to repeat studies such as this study, and to use data from national registries to obtain a broader view on how geographic altitude influences the progress of those patients suffering from neoplastic diseases.

The evidence of the risk of living at a high altitude could be an important key in the efficacy of anti-neoplastic therapy in Andean patients, and could be a significant factor in optimizing resources of public health in cancer screening; however, a more detailed study of molecular pathways and other risk factors is needed in the population included in this study.

\section{Ethnic differences in the risk of cancer}

A large number of Amerindian tribes, Africans, and European ancestors originate a complex ethnic diversity in the Ecuadorian population, in which Kichwa population is mainly located in the High Altitude [37]. This observation is important considering our results; however, there are at least 32 Kichwa tribes [38]. The identification of genetic differences in diverse ethnic groups could improve the understanding of risk factors to improve the medical evaluation and also to understand the possible response and outcomes in cancer therapeutic [39]. However, there is a lack of investigations about the genetic variability between Ecuadorian people living at HR and LR, in the types of cancer included in this study.

\section{Conclussion}

According to our findings, geographic elevation could be a condition that increases the risk of developing or dying from; gastric, colorectal, breast, cervical, liver and intrahepatic biliary cancer, or Lymphatic/Hematopoietic 
neoplasm. Therefore, the clinical evaluation of patients who are affected by these neoplasms should include their place of residence, as well as their socioeconomic and dietary conditions, to provide a more personalized treatment. Our results only corroborate a previous altitude study that shows a risk association of gastric cancer in mountainous regions of Pacific Latin America. Thus, we recommend investigating the effect of living at high altitude in wellcontrolled studies to clarify these findings.

\section{Acknowledgements}

We thank Dr. Paul Toapanta, from the Ministry of Public Health of Ecuador, for his valuable comments and Dr. Edwin Cevallos from the Hospital of Specialties of the Armed Forces $\mathrm{N}^{\circ}$ 1, Quito, Ecuador, for comments that improved the manuscript.

\section{References}

1. Jemal A, Bray F, Center MM, Ferlay J, Ward E, Forman D. Global cancer statistics. CA Cancer J Clin. 2011;61(2):69-90.

2. Curado MP, Bezerra de Souza DL. Cancer burden in Latin America and the Caribbean. Ann Glob Health. 2014;80:370-377.

3. Burtscher M. Effects of living at higher altitudes on mortality: a narrative review. Aging Dis. 2013;5(4):274-280.

4. Instituto Geográfico Militar. Quito [Spanish]. Available from: http://www.geoportaligm.gob.ec/portal/

5. Instituto Nacional de Estadísticas y Censos. Sistema Integrado de Consultas (REDATAM). Quito [Spanish]. Available from: http://www.ecuadorencifras.gob.ec/sistema-integrado-deconsultas-redatam/

6. Instituto Nacional de Estadísticas y Censos. Anuario de Nacimientos y Defunciones. Quito [Spanish]. Available from: http://www.ecuadorencifras.gob.ec/anuario-de-nacimientos-ydefunciones/

7. Instituto Nacional de Estadísticas y Censos. Anuario de Camas y Egresos Hospitalarios. Quito [Spanish]. Available from: http:// www.ecuadorencifras.gob.ec/anuario-de-camas-y-egresoshospitalarios/

8. U.S. Department of Health and Human Services. Principles of Epidemiology in Public Health Practice, Third Edition. Atlanta. Available from: https://www.cdc.gov/ophss/csels/dsepd/ss1978/ ss1978.pdf

9. Beall CM. Human adaptability studies at high altitude: research designs and major concepts during fifty years of discovery. Am J Hum Biol. 2013;25(2):141-147.

10. Calzada MJ, del Peso L. Hypoxia-inducible factors and cancer. Clin Transl Oncol. 2007;9(5):278-289.

11. Bigham AW, Lee FS. Human high-altitude adaptation: forward genetics meets the HIF pathway. Genes Dev. 2014;28:2189-2204. 12. Dodd KM, Tee AR. STAT3 and mTOR: co-operating to drive HIF and angiogenesis. Oncoscience. 2015;2(11):913-914.

13. Hashimoto T, Shibasaki F. Hypoxia-inducible factor as an angiogenic master switch. Front Pediatr. 2015 Apr 24;3:33. doi: 10.3389/fped.2015.00033.

14. Liu L, Ning X, Sun L, Zhang H, Shi Y, Guo C, et al. Hypoxia-inducible factor-1 alpha contributes to hypoxia-induced chemoresistance in gastric cancer. Cancer Sci. 2008;99:121-128. 15. Nakamura J, Kitajima Y, Kai K, Hashiguchi K, Hiraki M, Noshiro H, et al. HIF-1alpha is an unfavorable determinant of relapse in gastric cancer patients who underwent curative surgery followed by adjuvant 5-FU chemotherapy. Int J Cancer. 2010;127:1158-1171.

16. Torres J, Correa P, Ferreccio C, Hernandez-Suarez G, Herrero $\mathrm{R}$, Cavazza-Porro M, et al. Gastric cancer incidence and mortality is associated with altitude in the mountainous regions of Pacific Latin America. Cancer Causes Control. 2013;24(2):249-256.

17. Ryu SH, Chung YH, Lee H, Kim JA, Shin HD, Min HJ, et al. Metastatic tumor antigen 1 is closely associated with frequent postoperative recurrence and poor survival in patients with hepatocellular carcinoma. Hepatology. 2008;47:929-936.

18. Thongchot S, Yongvanit P, Loilome W, Seubwai W, Phunicom K, Tassaneeyakul W, et al. High expression of HIF$1 \alpha$, BNIP3 and PI3KC3: hypoxia-induced autophagy predicts cholangiocarcinoma survival and metastasis. Asian Pac J Cancer Prev. 2014;15(14):5873-5878.

19. Dales JP, Garcia S, Meunier-Carpentier S, Andrac-Meyer L, Haddad O, Lavaut MN, et al. Overexpression of hypoxiainducible factor HIF-1alpha predicts early relapse in breast cancer: retrospective study in a series of 745 patients. Int J Cancer. 2005;116:734-739.

20. West JB, American College of Physicians, American Physiological Society. The physiologic basis of high-altitude diseases. Ann Intern Med. 2004;141(10):789-800.

21. Key TJ, Allen NE, Spencer EA, Travis RC. The effect of diet on risk of cancer. Lancet. 2002;360(9336):861-868.

22. Fleischer AB Jr, Fleischer SE. Solar radiation and the incidence and mortality of leading invasive cancers in the United States. Dermatoendocrinol. 2016 Mar 28;8(1):e1162366. doi: 10.1080/19381980.2016.1162366.

23. Berger A, Loutre MF, Melice JL. Equatorial insolation: from precession harmonics to eccentricity frequencies. Clim Past. 2006;2:131-136.

24. Hart J. Cancer mortality in six lowest versus six highest elevation jurisdictions in the u.s. Dose Response.2010;9(1):50-58. 25. Scaranti M, Júnior G, Hoff AO. Vitamin D and cancer: does it really matter?. Curr Opin Oncol. 2016;28(3):205-209.

26. Reedy J, Krebs-Smith SM, Miller PE, Liese AD, Kahle LL, Park Y, et al. Higher diet quality is associated with decreased risk of all-cause, cardiovascular disease, and cancer mortality among older adults. J Nutr. 2014;144(6):881-889.

27. Cho YA, Lee J, Oh JH, Shin A, Kim J. Dietary Inflammatory Index and Risk of Colorectal Cancer: A Case-Control Study in Korea. Nutrients. 2016 Jul 30;8(8). pii: E469. doi: 10.3390/ nu8080469.

28. Bakken T, Braaten T, Olsen A, Kyrø C, Lund E, Skeie G. Consumption of Whole-Grain Bread and Risk of Colorectal Cancer among Norwegian Women (the NOWAC Study). Nutrients. 2016 Jan 13;8(1). pii: E40. doi: 10.3390/nu8010040.

29. Farvid MS, Eliassen AH, Cho E, Liao X, Chen WY, Willett WC. Dietary Fiber Intake in Young Adults and Breast Cancer Risk. Pediatrics. 2016 Mar;137(3):e20151226. doi: 10.1542/ peds.2015-1226.

30. Wroblewski LE, Peek RM Jr, Wilson KT. Helicobacter pylori and gastric cancer: factors that modulate disease risk. Clin Microbiol Rev. 2010;23(4):713-739.

31. Debets-Ossenkopp YJ, Reyes G, Mulder J, aan de Stegge BM, Peters JT, Savelkoul PH, et al. Characteristics of clinical Helicobacter pylori strains from Ecuador. J Antimicrob Chemother, 2003;51(1):141-145.

32. Díez-Padrisa N, Castellanos LG, PAHO Viral Hepatitis 
Working Group. Viral hepatitis in Latin America and the Caribbean: a public health challenge. Rev Panam Salud Publica. 2013;34(4):275-281.

33. Premoli G, González A, Villarreal J, Percoco T, Pietrocino P, Aguilera L. [Human papillomavirus; current view in biomedicine] Revista ADM. 2005;62(6):213-224. Spanish

34. de la Hoz-Restrepo F, Alvis-Guzmán N, Narváez J, ChocontáPiraquive LA. Evaluating the burden of disease caused by human papillomavirus in Bogota. Rev Salud Publica (Bogota). 2009;11(3):454-467.

35. Muñoz N, Bravo LE. Epidemiology of cervical cancer in Colombia. Colomb Med (Cali). 2012;43(4):298-304.

36. Ministerio de Salud Pública. Tomo I: Encuesta Nacional de Salud y Nutrición de la población ecuatoriana de cero a 59 años.
ENSANUT-ECU 2012. Quito [Spanish]. Available from: http:// www.ecuadorencifras.gob.ec/documentos/web-inec/Estadisticas Sociales/ENSANUT/MSP_ENSANUT-ECU_06-10-2014.pdf

37. Paz-Y-Miño C, Guillen Sacoto MJ, Leone PE. Genetics and genomic medicine in Ecuador. Mol Genet Genomic Med. 2015;4(1):9-17.

38. Jing L, Su L, Ring BZ. Ethnic background and genetic variation in the evaluation of cancer risk: a systematic review. PLoS One. 2014 Jun 5;9(6):e97522. doi: 10.1371/journal.pone.0097522.

39. López-Cortés A, Cabrera-Andrade A, Salazar-Ruales C, Zambrano AK, Guerrero S, Guevara P, et al. Genotyping the High Altitude Mestizo Ecuadorian Population Affected with Prostate Cancer. Biomed Res Int. 2017;2017:3507671. doi: $10.1155 / 2017 / 3507671$. 